\title{
Approaches to child protection case management for cases involving people with disabilities
}

NOTICE: This is the authors version of a work that was accepted for publication in Children and Youth Services Review. Changes resulting from the publishing process, such as peer review, editing, corrections, structural formatting, and other quality control mechanisms, may not be reflected in this document. Changes may have been made to this work since it was submitted for publication. A definitive version was subsequently published in Children and Youth Services Review.

\section{Citation:}

Lightfoot, E. \& *LaLiberte, T. (2006). Approaches to child protection case management for cases involving people with disabilities. Child Abuse \& Neglect, 30(4), 381-391.

\begin{abstract}
Objectives: This exploratory study examines the delivery of child protection services by county child protection agencies involving cases with a family member with a disability. Method: Telephone surveys were conducted with the directors or their designees of $89 \%$ of the child protection agencies in a Midwestern state. Respondents were asked about the policies and/or procedures for approaching cases involving a person with a disability and the barriers and strengths agencies have in serving people with disabilities.

Results: Only $6.7 \%$ of respondents reported their agency had a written policy related to serving persons with a disability. There were 18 different approaches to serving clients with a disability within child protection, with the most common being informally teaming for information, dual case assignment, and teaming with an outside consultant. Five counties had specialty workers who were experts in both child protection and disability. Barriers reported varied between rural and non-rural counties, with the most important barriers being lack of resources, lack of knowledge regarding disabilities, systems conflicts, and rural issues, such as lack of providers and lack of transportation. Strengths included accessing and coordinating services, individualizing services, good collaboration and creativity.

Conclusion: While few county agencies had any written policies, both formal and informal collaboration is happening at the individual level. The lack of standardization in providing services indicates a need for more attention to issues regarding disability within child protection, including more training for workers, the development of models of collaborative case management and the removal of systemic barriers.
\end{abstract}

Keywords: child maltreatment, abuse and neglect, disabilities, case management, child protection agencies

Acknowledgements: The authors gratefully acknowledge the county child protection agencies in Minnesota for participating in this study. This study was supported by the Minnesota Agricultural Experiment Station and the University of Minnesota Center for Advanced Studies in Child Welfare. 


\section{Introduction}

While the disproportional incidence of maltreatment experienced by children with disabilities has been noted for quite some time (Ammerman, 1989), there has been very little research on how the child welfare system responds to children with disabilities. Understanding how the child welfare system currently manages services to people with disabilities is necessary for making recommendations on future training of child protection workers or future collaborative efforts. This exploratory study examines the delivery of services by child protection services (CPS) agencies to children or family members with a disability.

\section{Background}

Estimates of maltreatment of children with disabilities range from 1.7 times greater than maltreatment of children without disabilities (Westat, 1993) to 3.4 times greater (Sullivan \& Knutson, 2000). Sullivan \& Knutson (2000) estimated that the rate of maltreatment for children with disabilities was $31 \%$. There has recently been a call for child maltreatment researchers to include disability status in child welfare research to help improve the knowledge about the vulnerability of children with disabilities (Kendall-Tackett, Lyon, Taliaferro, \& Little, 2005).

Despite the knowledge that children with disabilities are experiencing high rates of maltreatment, there is little knowledge regarding how the child welfare system provides services to such children. First, there is limited information collected by states on children with disabilities within the child welfare system. The Child Abuse Prevention and Treatment Act of 1988 (CAPTA) does not require states to collect data on disability status, and many states have not collected such data (Bonner, Crow, \& Hensley, 1997; Camblin, 1982). Despite recent calls from the American Psychological Association for states to include disability status in their records (American Psychological Association, 2003), preliminary findings from a study in 2003 found that there has been a decline in states collecting such information in the past decade (Shannon \& Agorastou, 2003).

There is even less information on how CPS agencies actually serve clients with disabilities. There are only a few studies that peripherally touch on the topic. Manders (1996), using case vignettes with child protection workers in Georgia, found that workers experienced discomfort when working with children with a variety of disabilities. In a survey of a convenience sample of child protection workers, Orelove, Hollahan \& Myles (2000) found that less than 9\% of child protection workers were very knowledgeable around the issues of child maltreatment of children with disabilities, though almost all survey respondents expressed a willingness to attend future training on the topic.

Despite the minimal research on child protections management of cases involving children with disabilities, there is a growing literature discussing appropriate child welfare practice with children with disabilities. The National Symposium on Abuse and Neglect of Children with Disabilities in 1994 identified a number of ways that the social service system could be improved, which included training child welfare workers on disability issues and improved interagency collaboration and coordination (National Symposium on Abuse and Neglect of Children with Disabilities, 1995). Similar calls for collaboration and/or training have come from a variety of sources (American Psychological Association, 2003; Goldson, 1998; Krahn, Thorn, Sokoloff, Hylton, \& Steinberg, 2000; Rogow \& Hass, 1999; Shannon \& Agorastou, 2003; Sobsey, 1994). There have also been a growing number of training materials designed for child protection workers which aim to provide knowledge about disability issues, including such topics as effective communication with people with disabilities, community disability resources, and 
interdisciplinary collaboration (Georgetown University Child Development Center, 2001; Hughes \& Rycus, 1998; O.Neill, 2002; Partnership for People with Disabilities, 2003; Struck, 1999).

With this new emphasis on improving child protection services for children with disabilities, and since no previous study has examined how CPS manages cases involving such children, we developed an exploratory study to address the following: what policies, plans and/or procedures do county CPS agencies follow to address the needs of children and family members with disabilities and what do county CPS agencies view as their barriers and strengths in serving people with disabilities?

\section{Methods}

This study gathered information from county CPS agencies within the state of Minnesota. While Minnesota is more racially homogeneous than many states, the rural-urban diversity between counties provides a good opportunity for rural/urban comparisons. Minnesota has 40 counties that have less than 20,000 total residents and 8 counties with over 100,000 residents. For analysis purposes, non-rural counties include any county that is part of a Metropolitan Statistical Area (MSA), and all others are rural counties, as per the Federal Office of Management and Budgets definition. Minnesotas non-rural counties include counties in the Twin Cities MSA and those in smaller MSAs in the state. There are 66 rural counties and 21 non-rural counties.

The data for this study come from a telephone survey with the directors of all county CPS agencies in the state. Minnesota is one of 13 states that operate a county administered child protection system, though a recent review of CPS agencies found that in practice, counties have primary responsibility for child protection functions in 36 states (U.S. Department of Health and Human Services, 2003). While Minnesota has 87 counties, several rural counties share administrative responsibilities, thus there are 84 total county CPS agencies in the state. Interview subjects were directors, or their representatives, from the county CPS agencies in Minnesota. The response rate was $89 \%$, with 75 out of the 84 county agencies participating in the telephone survey. The position of the person being surveyed included: $68 \%$ child welfare supervisors, $16 \%$ county directors, $8 \%$ child welfare unit managers, $6.7 \%$ child protection social workers, and $1.3 \%$ developmental disabilities manager. In most of the rural counties, there are no child protection unit managers, but rather there is one child protection supervisor for all child protection workers in the county, and this person reports directly to the county director of social services.

The telephone interviews took place from December 2002 through March 2003. A 15-20 minute, semi-structured interview was used to obtain information on the agencys approaches to cases involving individuals with a disability. Due to the exploratory nature of the study, openended questions were preferable because too much structure would have limited context description (Miles \& Huberman, 1994). Respondents were asked about policies and procedures for working with clients with disabilities, best practices, available resources, and barriers to providing services. Respondents were not given a definition of disability, but rather were asked to answer questions based upon how their county defined disability. Respondents were also not asked to limit their discussion to children with disabilities, but could also talk about any family member who had a disability, including parents with a disability. The study was approved as an exempt study by the office of the University of Minnesota Institutional Review Board.

Two researchers with extensive experience in the fields of disability and child protection collaborated in data analysis. A starting list of codes was developed from the research questions and known problem areas (Miles\& Huberman, 1994). The researchers first reviewed the transcribed data from the telephone interviews for themes. Researchers independently coded each interview 
using the established start list. Phrases, sentences, and implied meaning in survey data were coded. Researchers then reconciled the two sets of coded data, adding additional themes to those first established, grounding those codes empirically in the study (Miles \& Huberman, 1994). Researchers reviewed all interview data again to ensure uniform application of new themes amongst those interviews coded first to those coded last, and collapsed similar codes into broader codes. Coded data were then entered into SPSS for descriptive analysis and for comparisons between rural and non-rural counties.

\section{Results}

Policies. Respondents were first asked whether they had any knowledge of either county or CPS agency policies relating to serving people with disabilities within child protection. Of the respondents, $53.3 \%$ reported having no knowledge of any such policies related to disability. Only five counties $(6.7 \%)$ reported that they had a written policy related to procedures for cases involving people with disabilities. The remaining $40 \%$ reported an awareness of a county policy pertaining to disability accommodations, such as the provision of sign language interpreters.

Approaches to Cases with a Person with a Disability. When respondents were asked to describe the ways their agency approached child protection cases in which the child and/or the parent had a disability, 18 different approaches were described (Table 1), with a mean of 3.4 approaches used per county. The approaches loosely fit into six different groupings: 1) Formal Case Management, 2) Informal Case Management, 3) Collaborative Approaches, 4) Training and Information, 5) Systems-Related Approaches, and 6) Practice Approaches. The approaches, which did not differ significantly based on rural or non-rural location, are described below.

\section{Insert Table 1 About Here}

Formal case management approaches are formal arrangements that agencies have developed for working with cases involving people with disabilities. The two main formal approaches are dual case assignment and specialty child protection workers. Dual case assignment is when a case is formally opened in both child protection and another unit, such as development disabilities. More than half of the respondents cited dual case assignment as a regular case management approach (52\%). Some agencies also designated certain child protection workers as specialty child protection workers, workers who specialize in cases involving people with disabilities. These workers were responsible for many or all of the cases in the CPS agency that involve a child and/or a parent with a disability. One larger agency had an entire specialty unit, working only with cases involving a disability. The specialty worker approach was much less frequent, with only five counties (6.7\%) using specialty workers. In addition, one smaller county had only generalist workers, and thus all county workers had clients involved in both disability and child protection systems (1.3\%). While this county did not establish a generalist model specifically for working with these cases, this arrangement had some of the same benefits as the specialty child protection worker approach.

Informal case management approaches include approaches that involved special case management of a case involving a person with a disability; but these were approaches that depended on the particular child protection workers currently on staff. For example, nine counties $(12 \%)$ noted that they assign some or all cases involving a client with a disability to a CPS worker with experience in disabilities. These workers act unofficially or informally as specialty workers. If 
the worker leaves his or her position, the agency may no longer have a person specializing in cases involving a disability. Similarly, there were several counties that allow workers to self-select cases $(2.7 \%)$, in which workers who happen to have a professional or personal interest in disabilities have the opportunity to select such cases.

Collaborative approaches involve collaborating or teaming with people either inside or outside the county on a case-by-case basis. The approach cited most frequently was the collaborative approach, teaming for information (70.7\%). In these situations, a child protection worker informally teamed a case involving a person with a disability with another county professional who can provide information regarding financial resources, services, interviewing skills or other information on an informal basis. This can include informal questions via hollering over the cubicle, a telephone call to a disability worker located in a different building, or a consultative meeting with another worker. Other collaborative approaches included the use of a consultant in the community with expertise in disability issues (41.3\%), active consultation with county professionals in disability units $(16 \%)$, and teaming all child protection cases with a disability worker $(13.3 \%)$.

Training and Information. Many respondents also discussed acquiring additional information through training or data gathering related to clients with a disability. Nearly one third of the respondents mentioned that their workers were encouraged to attend trainings related to disability issues (30.6\%), and others said their workers obtained disability information from the required core training that all child protection workers attend (14.7\%). A number of respondents also mentioned the use of research and data gathering, particularly on the Internet, to acquire more information on particular cases involving clients with a disability (10.7\%).

Systems Approaches. There was a loose grouping of responses that related to system approaches. For example, some respondents discussed how their child protection workers made a point of screening a case to see if the case had an open disability case, by using the state social service information system (SSIS) and/or through interviewing the family (8\%). Two rural counties discussed how they checked with other neighboring counties to determine if the family had a prior child protection or disability case. A number of respondents discussed that their workers referred cases involving a person with a disability that did not have an open case to the appropriate disability unit, such as developmental disabilities, so the clients could obtain voluntary services (20\%). In some instances, when cases were referred to the disability unit, the child protection case was closed, but more frequently, the family would then have cases opened in both units, and would thus have dual case assignment. Eleven respondents (14.7\%) also discussed how they make accommodations to clients with disabilities, such as providing sign language interpreters or meeting with clients at accessible locations.

Practice approaches. Finally, there were respondents who discussed practice approaches to working with clients with a disability. Nine counties reported assessing for safety incorporating disability issues (12\%). In these counties, risk factors associated with a disability, such as increased vulnerability for a child with a disability or increased risk of parental neglect due to a parents disability, were incorporated into safety assessments at intake, assessment, ongoing work with the family, placement or reunification, and/or case closure.

Barriers. Respondents next described the barriers their agencies faced in providing appropriate services for people with disabilities. Respondents could list multiple barriers, with a mean of 4.1 barriers described by each respondent and 35 different types (See Table 2 for the most frequent barriers). Respondents frequently cited issues related to a specific disability as a barrier in both rural (47.3\%) and non-rural counties (35\%). Factors related to specific disabilities included 
communication challenges, behaviors associated with particular disabilities, and the chronic nature of some disabilities, such as mental illness.

\section{Insert Table 2 About Here}

When prompted for detailed information on barriers, respondents discussed system-level barriers more frequently. System-level barriers varied greatly between rural and non-rural counties. Respondents from non-rural counties reported their most significant barrier was a lack of financial resources (45\%). Many also discussed the lack of disability knowledge by child protection workers and other professionals, such as law enforcement or the judicial system, as well as lack of knowledge by the community overall (35\%). Likewise, 30\% discussed systems conflicts relating to bureaucracy and red tape to providing appropriate services. For example, a family of an at-risk child may be eligible for supportive services through a Medicaid waiver; however, only a disability worker can obtain these services, not a child protection worker. One-fifth of the respondents cited barriers related to the expedited time frames mandated by the Adoption and Safe Families Act of 1997 (ASFA). While there can be exceptions to these time frames, some respondents discussed how these timelines can be a barrier, such as for parents with disabilities who may need extra time to learn parenting skills or families who need more time to obtain appropriate resources to support a child with a disability.

The barriers discussed by respondents in rural counties often related to the rural nature of their county. In fact, $41.8 \%$ stated that being a rural county was in itself a barrier. Others mentioned rural-related concerns, such as lack of providers (47.3\%), driving distances (25.5\%), lack of transportation (25.5\%), and lack of specialized providers (25.5\%). Lack of knowledge about disability issues was cited by $30.9 \%$ of the respondents, with some mentioning that there were so few people with disabilities in their counties that their agency does not have a critical mass of cases to develop the appropriate expertise (20\%).

Strengths. Respondents also discussed the strengths that their CPS agency had in working with cases involving a family member with a disability. Overall, respondents described 25 strengths, with a mean response of 2.5 strengths per county (Table 3 ). For non-rural counties, respondents identified their biggest strength as being able to access and coordinate services effectively for cases involving a client with a disability (45\%). Non-rural respondents also highlighted their ability to collaborate well, particularly in dual case assignment arrangements $(35 \%)$. One-fifth of the non-rural respondents discussed the creativity and innovation of the child protection workers as a strength, and other strengths included community involvement (15\%), holistic approach (15\%), good relationships with clients and families (15\%) and the presence of well-developed services (15\%).

\section{Insert Table 3 About Here}

Rural respondents highlighted slightly different strengths. The top rural strength was the ability to individualize and tailor services for families that had a member with a disability (40\%). For example, one respondent said, when you have a low incidence of disabilities like we do, it works well for each client to have individualized servicesOur numbers arent high enough to develop programs and plans. A unique rural strength $(18.2 \%)$ was that because counties were small, the workers were familiar with the other county social workers and providers, and were thus able to collaborate and individualize services effortlessly. 


\section{Discussion}

The findings show that there is no standard approach in CPS agencies to managing cases involving people with disabilities in the state of Minnesota. Counties use a myriad of approaches, which can be grouped into six categories, including formal case management approaches, informal case management approaches, collaborative approaches, training and data gathering, systems approaches, and a practice approach. Very few counties (6.7\%) have specialist workers who are experts in both child protection and disability issues, while another $12 \%$ happened to have this arrangement based on personnel with previous disability experience.

Practice guidelines are calling for more attention on collaboration for providing appropriate child protection services to children with disabilities (American Psychological Association, 2003; Goldson, 1998; Krahn et al., 2000; National Symposium on Abuse and Neglect of Children with Disabilities, 1995). The findings from this study show that both formal and informal collaboration is happening at the worker or case level. Over half of the respondents indicated that cases involving people with disabilities had dual case assignment, and nearly threequarters said that the workers in their agency team with other county workers to gain information on serving people with disabilities. The respondents also indicated in both rural and urban counties that collaborating well was a strength of their CPS agencies. Nevertheless, while workers may be collaborating well, there still remain large systems conflicts that may impede effective collaboration.

When evaluating this studys findings, the methodological limitations should be noted. This exploratory study focused only on Minnesotas CPS agencies, and thus its findings cannot be generalized to other states. Further, as open-ended questions were employed, it is possible that respondents did not report some of their county approaches, barriers or strengths. As respondents were administrators, they may not have direct knowledge of actual agency practices. Additionally, one respondent per county cannot give a fully accurate description of a countys formal and informal practices. Finally, respondents may be presenting a much better picture than actually occurs in the field. The findings from this study serve as a framework for future research on this topic. Next steps should involve a follow-up study using standardized questions based on results from this exploratory survey, and should be conducted with both front-line workers and administrators.

This study is the first to investigate how public CPS agencies manage cases involving children with disabilities. Knowledge of the variety of approaches counties use helps provide a baseline from which future collaboration and training can be structured. The lack of standardization in providing services to people with disabilities within CPS and the many barriers county CPS agencies face indicate a need for more attention to disability issues within child protection, including more training for workers, the development of models of collaborative case management and the removal of systemic service barriers.

\section{$\underline{\text { References }}$}

American Psychological Association. (2003). Resolution on the maltreatment of children with disabilities. Washington, DC: American Psychological Association.

Ammerman, R. T. (1989). Abuse and neglect in psychiatrically hospitalized multihandicapped children. Child Abuse \& Neglect, 13, 335-343.

Bonner, B. L., Crow, S. M., \& Hensley, L. D. (1997). State efforts to identify maltreated children with disabilities: A follow-up study. Child Maltreatment, 2(1), 52-60. 
Camblin, L. (1982). A survey of state efforts in gathering information on child abuse and neglect in handicapped populations. Child Abuse \& Neglect, 6, 465-472.

Georgetown University Child Development Center. (2001). Serving children with disabilities: A video series for child welfare workers. Washington, DC: Georgetown University Child Development Center.

Goldson, E. (1998). Children with disabilities and child maltreatment. Child Abuse \& Neglect, 22(7), 663-667.

Hughes, R., \& Rycus, J. (1998). Developmental disabilities and child welfare. Washington, DC: Child Welfare League of America.

Kendall-Tackett, K., Lyon, T., Taliaferro, G., \& Little, L. (2005). Why child maltreatment researchers should include children.s disability status in their maltreatment studies. Child Abuse \& Neglect, 29(2), 147-151.

Krahn, G. I., Thorn, V. A., Sokoloff, K., Hylton, J., \& Steinberg, M. (2000). Every child special, every child safe: Protecting children with disabilities from maltreatment. Portland, OR: Oregon Health Sciences University.

Manders, J. E. (1996). Children with disabilities in the child protective services system: the impact of disability on abuse investigation and case management. Athens, GA: University of Georgia.

Miles, M., \& Huberman, A. M. (1994). Qualitative data analysis: An expanded sourcebook (2nd ed.). Thousand Oaks, CA: Sage Publications.

National Symposium on Abuse and Neglect of Children with Disabilities. (1995). Abuse and neglect of children with disabilities: Report and recommendations. Lawrence, KS: The Beach Center on Families and Disability, the University of Kansas, and the Erikson Institute of Chicago.

O.Neill, P. (2002). Abuse and Neglect of Children with Disabilities: A Collaborative Response. Richmond, VA: Partnership for People with Disabilities, Virginia Commonwealth Unviersity.

Orelove, F., Hollahan, D., \& Myles, K. (2000). Maltreatment of children with disabilities: Training needs for a collaborative response. Child Abuse \& Neglect, 24(2), 185-194.

Partnership for People with Disabilities. (2003). Abuse and Neglect of Children with Disabilities: A Collaborative Response. Richmond, VA: Partnership for People with Disabilities, Virginia Commonwealth Unviersity.

Rogow, S., \& Hass, J. (1999). The person within: Preventing abuse of children and young people with disabilities. Vancouver, BC: British Columbia Institute Against Family Violence.

Shannon, P., \& Agorastou, M. (2003). Children with disabilities who have been maltreated: Preliminary findings from a survey of state child welfare agencies. Paper presented at the Annual Meeting of the American Association on Mental Retardation, Chicago, IL.

Sobsey, D. (1994). Violence and abuse in the lives of people with disabilities: The end of silent acceptance? Baltimore, MD: Paul H. Brookes.

Struck, L. (1999). Assistance for special educators, law enforcement, and child protective services in recognizing and managing abuse and neglect of children with disabilities. Richmond, VA: Virginia Department of Social Services.

Sullivan, P., \& Knutson, J. (2000). Maltreatment and disabilities: A population-based epidemiological study. Child Abuse \& Neglect, 24(10), 1257-1273.

U.S. Department of Health and Human Services. (2003). National study of child protective services systems and reform efforts: A review of state CPS policy. Washington, DC: Office of the 
Assistant Secretary for Planning and Evaluation and the Administration for Children and Families, Children.s Bureau, U.S. Department of Health and Human Services.

Westat, I. (1993). A report on the maltreatment of children with disabilities. Washington,

DC: National Center on Child Abuse and Neglect.

Table 1

County Approaches to Managing Cases Involving People with Disabilities

\begin{tabular}{|c|c|c|}
\hline Type of Approach & Specific Approach & $\begin{array}{l}\text { Percent of } \\
\text { Responses }\end{array}$ \\
\hline \multirow[t]{3}{*}{ Formal Case Management } & Dual Case Assignment & $52.0 \%$ \\
\hline & Specialty CPS Workers & $6.7 \%$ \\
\hline & All Generalist County workers & $1.3 \%$ \\
\hline \multirow[t]{2}{*}{ Informal Case Management } & CPS Worker with Disability Experience & $12.0 \%$ \\
\hline & Self-Select Cases & $2.7 \%$ \\
\hline \multirow{5}{*}{ Collaborative Approaches } & Teaming: Active & $16.0 \%$ \\
\hline & Teaming: Information & $70.7 \%$ \\
\hline & Team Cases with Outside Consultant & $41.3 \%$ \\
\hline & Regularly Scheduled Team Opportunities & $12.0 \%$ \\
\hline & Team All cases & $13.3 \%$ \\
\hline \multirow[t]{3}{*}{ Training and Information } & Minnesota Core Training & $14.7 \%$ \\
\hline & Training & $30.7 \%$ \\
\hline & Research \& Data Gathering & $10.7 \%$ \\
\hline \multirow[t]{4}{*}{ Systems Approach } & Make New Referral to Disability Unit & $20.0 \%$ \\
\hline & Screen for the Presence of Disability or Worker & $8.0 \%$ \\
\hline & Check History with Counties & $2.7 \%$ \\
\hline & Make Accommodations & $14.7 \%$ \\
\hline Practice Approach & $\begin{array}{l}\text { Assess for Safety Incorporating Disability } \\
\text { Issues }\end{array}$ & $12.0 \%$ \\
\hline
\end{tabular}

Table 2. 
Frequency of Barriers Identified to Providing Effective Services

\begin{tabular}{|c|c|c|c|}
\hline \multicolumn{2}{|l|}{ Barriers, Non-Rural } & \multicolumn{2}{|l|}{ Barriers, Rural } \\
\hline Lack of resources & $45 \%$ & Lack of providers & $47.3 \%$ \\
\hline $\begin{array}{l}\text { Issues related to a specific } \\
\text { disability }\end{array}$ & $35 \%$ & $\begin{array}{l}\text { Issues related to a specific } \\
\text { disability }\end{array}$ & $47.3 \%$ \\
\hline $\begin{array}{l}\text { Lack of disability knowledge } \\
\text { by CPS, Professionals \& } \\
\text { Community }\end{array}$ & $35 \%$ & Rural county & $41.8 \%$ \\
\hline Systems conflicts & $30 \%$ & $\begin{array}{l}\text { Lack of disability knowledge } \\
\text { by CPS, Professionals \& } \\
\text { Community }\end{array}$ & $30.9 \%$ \\
\hline $\begin{array}{l}\text { Adoption and Safe Families } \\
\text { Act placement timeframes }\end{array}$ & $20 \%$ & Lack of resources & $27.3 \%$ \\
\hline Cases take a long time & $20 \%$ & Driving distances & $25.5 \%$ \\
\hline Lack of accommodations & $15 \%$ & $\begin{array}{l}\text { Lack of specialized providers } \\
\text { and/or services }\end{array}$ & $25.5 \%$ \\
\hline Lack of training & $15 \%$ & Transportation & $25.5 \%$ \\
\hline Waiting lists for providers & $15 \%$ & $\begin{array}{l}\text { Low incidence of disabilities } \\
\text { in county }\end{array}$ & $20.0 \%$ \\
\hline Lack of providers & $15 \%$ & Systems conflicts & $18.2 \%$ \\
\hline $\begin{array}{l}\text { Ineffective treatments } \\
\text { available }\end{array}$ & $15 \%$ & Lack of accommodations & $18.2 \%$ \\
\hline
\end{tabular}


Table 3.

Frequency of Strengths Identified in Providing Effective Services

\begin{tabular}{|l|l|l|l|}
\hline \multicolumn{2}{|l|}{ Strengths, Non-Rural } & \multicolumn{2}{l|}{ Strengths, Rural } \\
\hline $\begin{array}{l}\text { Accessing and coordinating } \\
\text { services }\end{array}$ & $45 \%$ & $\begin{array}{l}\text { Individualizing and tailoring } \\
\text { services }\end{array}$ & $40.0 \%$ \\
\hline $\begin{array}{l}\text { Collaborate well (Dual } \\
\text { Workers) }\end{array}$ & $35 \%$ & $\begin{array}{l}\text { Accessing and coordinating } \\
\text { services }\end{array}$ & $38.2 \%$ \\
\hline Creativity and innovation & $20 \%$ & Creativity and innovation & $27.3 \%$ \\
\hline Community involvement & $15 \%$ & $\begin{array}{l}\text { Collaborate well (Dual } \\
\text { Workers) }\end{array}$ & $21.8 \%$ \\
\hline Holistic approach & $15 \%$ & $\begin{array}{l}\text { Small agency so we know } \\
\text { each other well }\end{array}$ & $18.2 \%$ \\
\hline $\begin{array}{l}\text { Good relationship with clients } \\
\text { and families }\end{array}$ & $15 \%$ & $\begin{array}{l}\text { Good relationship with } \\
\text { clients and families }\end{array}$ & $18.2 \%$ \\
\hline $\begin{array}{l}\text { Well-developed services are } \\
\text { available }\end{array}$ & $15 \%$ & & \\
\hline
\end{tabular}

